\title{
AS RAÍZES DA TEORIA DOS JOGOS E COMPORTAMENTO ECONÔMICO: UMA ANÁLISE EPISTEMOLÓGICA A PARTIR DOS TRABALHOS DE JOHN VON NEUMANN, OSKAR MORGENSTERN E JOHN FORBES NASH
}

\author{
THE ROOTS OF GAME THEORY AND ECONOMIC BEHAVIOR: AN EPISTEMOLOGICAL ANALYSIS \\ FROM THE WORKS OF JOHN VON NEUMANN, OSKAR \\ MORGENSTERN E JOHN FORBES NASH
}

\author{
Angelica Pott de Medeiros ${ }^{1}$ \\ https://orcid.org/0000-0002-7418-344X
}

Submissão: 21/05/2020 / Aceito: 26/08/2020

\begin{abstract}
Resumo
O presente estudo tem como objetivo analisar sob um ponto de vista epistemológico a Teoria dos Jogos, baseando-se em von Neumann, Morgenstern e Nash, a partir de suas relevantes obras para o campo. Diante disso, foi realizada uma pesquisa bibliográfica visando sintetizar os principais aspectos epistemológicos e as principais correntes de pensamento científico e filosófico. A partir disso, foi possível avançar para a próxima etapa, que consistiu em uma análise documental das obras sob a ótica da epistemologia. Os resultados indicam que a Teoria dos Jogos aborda matematicamente o processo de tomada de decisão de agentes, cujo objetivo principal é a maximização da utilidade dos jogadores, que pautam-se em decisões racionais. Dessa forma, em seus conceitos é possível identificar, sobremaneira, características do utilitarismo e do positivismo.
\end{abstract}

Palavras-chave: Teoria dos Jogos. Epistemologia. Positivismo.

\begin{abstract}
The present study aims to analyze the Game Theory from an epistemological point of view, based on von Neumann, Morgenstern and Nash, from their relevant works for the field. Therefore, a bibliographic research was carried out aiming to synthesize the main epistemological aspects and the main currents of scientific and philosophical thought. From this, it was possible to proceed to the next stage, which consisted of a documentary analysis of the works from the perspective of epistemology. The results indicate that Game Theory mathematically addresses the decision-making process of agents, whose main objective is to maximize the usefulness of the players, who are guided by rational decisions. Thus, in its concepts it is possible to identify, in a great way, characteristics of utilitarianism and positivism.
\end{abstract}

Keywords: Game Theory. Epistemology. Positivism.

\footnotetext{
${ }^{1}$ Doutoranda em Administração na Universidade Federal de Santa Catarina (UFSC), docente na Universidade Federal de Santa Maria (UFSM).
} 


\section{INTRODUÇÃO}

Desde os anos de 1940, a teoria dos jogos tem apresentado grande utilidade estratégica. Inicialmente usava-se para fins militares, utilizada com grande sucesso na $2^{\mathrm{a}}$ Guerra Mundial, na Guerra Fria e na Guerra da Coréia. Dentre os pressupostos da teoria, destaca-se a perspectiva de que as ações de um dos jogadores baseia-se no que "ele pensa que o oponente pensa", o que conduziu os Estados Unidos a forçar o adiamento de um conflito contra a União Soviética (ALMEIDA, 2003). Sousa (2005) argumenta que nesse período entre guerras, a teoria dos jogos ganhou destaque e passou a uma formalização mais rigorosa. Além disso, instaurou-se uma polêmica acerca do pioneiro dessa abordagem. Diante disso, devido ao seu artigo datado de 1928, John von Neumann é considerado o precursor da abordagem mais recente, porém, isso não é consensual. Dessa forma, os anos 40 foram de intensa discussão sobre comportamentos, matemática e jogos. Ao passo que, em 1944 foi publicado o livro "Teoria de jogos e comportamento econômico" ${ }^{2}$ de autoria de von Neumann e Morgenstern.

Tal publicação consistiu em uma nova proposta para a resolução de problemas econômicos, baseando-se na matemática. Apesar dessas bases já participarem das análises econômicas naquela época, os autores defendiam que a matemática dos jogos apresentava utilidade na aplicação sobre o comportamento humano, no qual, para eles, era a característica principal dos processos econômicos (SOUSA, 2005). Posteriormente, nos anos 50, o norteamericano John Forbes Nash apresentou novos conceitos à teoria dos jogos, revolucionando a economia com seu conceito de equilíbrio. Nash havia sido aluno de von Neumann, e acabou rompendo com um paradigma econômico que consistia no pressuposto básico da teoria desenvolvida por von Neumann (ALMEIDA, 2003).

Diante da formação e do desenvolvimento desse campo de conhecimento, o presente estudo tem como objetivo analisar sob um ponto de vista epistemológico a teoria dos jogos, baseando-se em von Neumann, Morgenstern e Nash, a partir de suas relevantes obras. Destacase que a temática já vem sendo explorada pela literatura, haja vista a possibilidade da utilização da teoria dos jogos para a compreensão de situações de conflito e/ou cooperação. Desse modo, verificam-se aplicações em interações estratégicas entre organizações (SELOTI JR., 2008; ABBADE, 2009; MARINHO, 2011; FREITAS; ALVES, JUNGES, 2016; DA SILVA et al., 2016; ANDRADE; DAMÁZIO, BARRETO, 2016), gestão de custos (FIGUEIREDO, 1994),

\footnotetext{
${ }^{2}$ Do inglês "Theory of games and economic behavior".
} 
mediação de conflitos no âmbito do judiciário (ALMEIDA, 2003; SPENGLER; NETO, 2009), relações internacionais e na teoria da escolha racional (SOUZA, 2003), entre outros.

Observa-se também análise sobre as motivações epistemológicas da referida teoria (SOUZA, 2005). Porém, o estudo mencionado limita-se a obra pioneira de von Neumann e Morgenstern. Ao passo que, o presente estudo amplia a análise ao considerar as obras de Nash. Cabe ressaltar que parte-se do pressuposto da importância de análises epistemológicas, tendo em vista que a epistemologia é um saber interdisciplinar, que investiga a produção de conhecimento científico tanto do ponto de vista lógico, quanto linguístico, ideológico, sociológico e antropológico (SERVA, 2012).

Para atender ao desenvolvimento do problema proposto, o trabalho está constituído em mais quatro seções, além da introdução. Inicialmente, na seção dois são apresentados os fundamentos básicos de epistemologia nas ciências sociais, posteriormente são discorridos os procedimentos adotados na realização do estudo. Na quarta seção são discutidos aspectos da análise epistemológica do tema, e por fim, são delineadas as considerações finais do estudo.

\section{EPISTEMOLOGIA NAS CIÊNCIAS SOCIAIS}

Nessa seção são abordados alguns aspectos sobre epistemologia e as suas correntes: racionalismo/empirismo, positivismo/utilitarismo e o sistemismo, que caracterizam-se como abordagens do paradigma dominante em ciências sociais. Além destes, discorre-se sobre a dialética. Essa contextualização tem por objetivo elencar os principais paradigmas de forma a possibilitar uma melhor análise do posicionamento de Von Neumann, Morgenstern e Nash.

A epistemologia consiste no estudo da ciência, a partir de seus fundamentos, procedimentos, organização, desenvolvimento, assim como o funcionamento de seus resultados. Dessa forma, os limites do domínio de sua investigação são incertos, fator que dificulta a sua conceituação e a delimitação de seu espectro investigativo. Além disso, possui um aspecto interdisciplinar, possibilitando o estudo da produção de conhecimento de um ponto de vista lógico, linguístico, sociológico, ideológico, etc. Aspectos que permitem tanto o confronto, quanto a interface entre diferentes concepções de conhecimento, das áreas de saber e das perspectivas epistemológicas (JAPIASSU, 1991).

Ademais, o autor supracitado argumenta que em relação à epistemologia, o questionamento da ciência acarretou em uma ampliação de seu escopo, partindo da análise do saber científico globalmente considerado, para contar também com análises de campos 
específicos. Dessa forma, pode-se inferir atualmente sobre uma epistemologia geral, orientado ao saber científico como um todo, e de epistemologias especificas, em que cada unidade possui seus saberes científicos, que são elaborados por administradores, economistas, sociólogos, biólogos, entre outros.

Apesar do caráter interdisciplinar, a epistemologia consiste em um tema de pesquisa de filósofos sobre a ciência, e para a ciência, mas não objeto de estudo dos próprios cientistas. Assim, as filosofias acabaram por desenvolver filosofias da ciência e teorias do conhecimento com o objetivo de: a) evidenciar os meios de conhecimento científico; b) esclarecer os objetos em que determinado conhecimento se aplica; e c) estabelecer a validade deste conhecimento. Ademais, as três funções clássicas da filosofia da ciência consistem em: a) situar o lugar de conhecimento científico dentro do domínio do saber; b) definir os limites do conhecimento científico; e c) investigar a natureza da ciência (JAPIASSU, 1991).

\section{O empirismo e o racionalismo}

Em se tratando de empirismo e racionalismo, destacam-se as obras de Francis Bacon (1561-1626), René Descartes (1596-1650) e Immanuel Kant (1724-1804). Bacon, defensor do empirismo, elucida a existência de duas fontes de geração e de propagação de doutrinas, um destinado ao cultivo das ciências e o outro para a descoberta científica, ou seja, o primeiro método consiste na antecipação da mente e o segundo na interpretação da natureza. Argumentando que, o primeiro caminho será de longe o caso da maior parte dos homens, já o segundo, é para os verdadeiros filhos da ciência, e que desejam ir mais além. No empirismo de Bacon, a melhor demonstração consiste na experiência, desde que apresente rigor científico. Ou seja, é preciso utilizar um método ordenado, identificando os seus axiomas. Dessa forma, apresenta seu método de interpretação baseado na indução, que consistem no que ele nomeia de tábuas da investigação (BACON, 1979).

Por outro lado, o racionalismo de Descartes ressalta o método dedutivo para se desviar dos erros dos sentidos, os quais podem enganar o sujeito que busca a verdade. Dessa forma, sugere um método para conduzir a razão na busca da verdade dentro da ciência a partir dos seguintes preceitos: a) jamais considerar alguma coisa como verdadeira que não seja conhecida como tal; b) dividir cada uma das dificuldades analisadas em tantas parcelas quantas fossem possíveis e necessárias para melhor resolvê-las; c) conduzir os pensamentos em ordem, partindo dos mais fáceis de conhecer e mais simples; e d) fazer enumerações completas e revisões 
gerais, para haver a certeza de nada omitir. Pode-se observar, que assim como Bacon, Descartes defende a utilização de um método para a geração de conhecimento, porém Descartes alega que o racionalismo é o caminho para a verdade. Sendo necessário questionar as verdades, ao passo que, a verdade seria aquilo que resiste às dúvidas (DESCARTES, 1979).

Porém, Immannuel Kant, em "Crítica da razão pura", defende que todo o conhecimento deriva da experiência, mas também considera as inferências racionalistas, ou seja, os conhecimentos a priori que consiste na razão pura, e os conhecimentos a posteriori, ou seja, empíricos e da experiência (KANT, 2015). Dessa forma, Kant reconstitui os sentidos na ciência, desconstituído pelo método cartesiano. Ele não nega que os objetos nos afetam através dos sentidos, e mostra que a sensibilidade não é suficiente para falar em conhecimento. Assim, reconhece o preceito do empirismo em relação à experiência, e não dispensa o pressuposto do racionalismo, inaugurando uma "nova forma de pensar" em filosofia (PIMENTA, 2008).

\section{O positivismo e o utilitarismo}

Jeremy Bentham (1748-1832) em sua obra "Uma introdução aos princípios da moral e da legislação" propõe a construção de um sistema de filosofia moral, conhecido por utilitarismo, denominação dada pela ideia de que a moral é estabelecida pela utilidade (princípio estabelecido por Hume). A $1^{\circ}$ Lei da Natureza é a busca do prazer e a prevenção da dor, baseando-se na crença de que a felicidade pessoal devia seguir em direção à felicidade alheia. Fundamentando a conduta social e individual, e a obediência ao Estado na medida em que a felicidade geral viria como contribuição, dado pelo Princípio da Utilidade (BENTHAM, 1979).

Porém, Bentham buscou tornar a ciência moral uma ciência exata, através da quantificação das vantagens e desvantagens, com a soma de todos os valores dos prazeres de um lado, e de todas as dores de outro. Caso essa soma for favorável ao prazer indica a tendência boa do ato, e se for favorável a dor, indica a tendência má do ato. Assim, ele defendia que a sua doutrina devia servir de base ao direito penal, a partir da avaliação da motivação das ações para determinar as punições, através da positivação do direito (BENTHAM, 1979).

Posteriormente, com base em algumas características utilitaristas, e em reação ao idealismo, Augusto Comte (1798-1857) estabeleceu o positivismo, que por si só, exige maior respeito para a experiência e os dados positivos, limitando-se a experiência imediata, pura e sensível, como já fizera o empirismo. Caracteriza-se também como uma tentativa de aplicação 
dos princípios e métodos das ciências naturais na filosofia. Sendo essa última reduzida à metodologia e à sistematização das ciências. Além disso, Comte defendia que a civilização humana atravessava três grandes fases: a teológica, a metafísica e a positiva. Nessa última fase o culto da divindade é substituído pelo culto da humanidade, cerne da religião positiva (PADOVANI; CASTAGNOLA, 1990).

O positivismo se deu primeiramente na França através do próprio Comte e de Hipólito Taine (1828-1893). Na Inglaterra o maior representante do positivismo foi João Stuart Mill (1806-1873), defensor do raciocínio indutivo para a distinção do que é, e o que não é científico, e também do utilitarismo moral. A partir disso, o critério de cientificidade passou a consistir na verificação, em forma de observação empírica. Além de Mill, destaca-se Herbert Spencer (1820-1903) que sistematizou o positivismo e aplicou a lei da evolução a todo campo da experiência (PADOVANI; CASTAGNOLA, 1990; DEMO, 1985).

Os membros do Círculo de Viena tido como idealizadores do "positivismo lógico" e também dos pressupostos do positivismo clássico, defendiam a condição de validação dos argumentos teóricos. A possibilidade de refutar as teorias que carecem de significado científico ficou conhecido como "princípio de verificabilidade” (DORTIER, 2000). Karl Popper (19021994) influenciado pelas discussões do Círculo de Viena se opôs a concepção tradicional da ciência, defendendo que a partir da verificação não haveria garantia de que o enunciado universal fosse verdadeiro. Propondo um critério de demarcação através do falseamento, preocupado em confirmar que a teoria era falsa, e quando a teoria resistisse a refutação pela experiência, poderia ser considerada comprovada (POPPER, 1980).

\section{O funcionalismo}

Conforme o argumento do sociólogo Émile Durkheim (1858-1917) os fatos sociais são as formas de agir, pensar e sentir, exteriores aos indivíduos e dotados de um poder coercitivo. Dessa forma, o fato social se reconhece através de seu poder de coação diante dos indivíduos, não excluindo a personalidade individual. A partir do conceito de função, o funcionalismo é fortemente relacionado a divisão do trabalho (DURKHEIM, 1978).

Sob o ponto de vista antropológico de Bronisław K. Malinowski (1884-1942), pioneiro na observação participante e fundador da antropologia, o funcionalismo centrou-se na compreensão da natureza de fenômenos culturais, sendo necessário definir os fenômenos de acordo com as funções e a forma. Além disso, o autor defendia que através da teoria funcional 
era possível produzir uma análise concreta da cultura em instituições e seus aspectos (MALINOWSKI, 1970).

Posteriormente, Alfred R. Radcliffe-Brown (1881-1955) sistematizou a função, e defendeu que o conceito de função aplicada as sociedades parte da analogia entre a vida social e a vida orgânica. A sociedade no curso de sua história pode mudar a sua forma estrutural, sem qualquer descontinuidade. Assim, a função consiste na contribuição que uma atividade específica proporciona à atividade total a qual faz parte. Dessa forma, a função de determinado costume social é a contribuição que este oferece à vida social total. O que implica na necessidade de investigação mais profunda possível de todos os aspectos da vida social (RADCLIFFE-BROWN, 1973).

Conforme Evans-Pritchard (1902-1973) foram Spencer e Durkheim que chamaram a atenção dos antropólogos sociais para a análise funcional. E, apesar de apresentar algumas críticas ao funcionalismo, se declara como tal (EVANS-PRITCHARD, 1972). Em se tratando das principais escolas funcionalistas na análise das organizações, Séguin e Chanlat (1987) argumentam que é possível identificar algumas concepções em comum, tais como: a) concepção sistêmica e sincrônica (as organizações são definidas a partir de um conjunto em que as partes são racionadas umas com as outras, podendo ser indivíduos ou grupos, havendo a necessidade de uma coordenação em busca de uma maior eficiência, que é satisfeita por uma estrutura de autoridade, assim, as atividades de certas pessoas, são sistematicamente planejadas por outras pessoas); b) concepção teleológica da organização (orientação das atividades para o alcance de certos objetivos e metas); c) concepção "a-histórica" da organização; e d) concepção integradora e harmônica da organização.

\section{O sistemismo}

A partir da necessidade de um desenvolvimento mais aprofundado em sociologia sobre sistemas sociais (BUCKLEY, 1971). O sistemismo continua o caminho iniciado pelo funcionalismo, havendo uma evidente aproximação e parentesco, principalmente na aplicação em ciências sociais. O ponto de vista do sistema apresenta uma acentuação metodológica particular, mas também, apresenta um parentesco com o estruturalismo. Haja vista que o sistema necessita de uma estrutura, como um feixe de relações entre os elementos que o compõe. Seu conceito é voltado à inter-relação entre as partes, que consiste em uma 
distribuição de partes que se associam e se completam, conforme observa-se no conceito de Walter Buckley (1922-2006), que considera o sistema como um complexo de elementos e componentes direta e indiretamente relacionados numa rede causal, de sorte que cada componente se relaciona pelo menos com alguns outros, de modo mais ou menos estável, dentro de determinado período de tempo (DEMO, 1985).

Um dos maiores problemas do sistemismo é a delimitação do sistema, para que seja possível distinguir um sistema de outro. Dessa forma, a corrente acredita na máxima de que o todo é maior do que a soma das partes, privilegiando a síntese e a visão da totalidade. Assim, a soma das partes não é a simples adição numérica, mas a sua agregação não organizada. Uma das suas características fundamentais é a capacidade de absorver informação e de se adaptar às novas situações, caso contrário, o sistema desaparece. Esse conceito consiste no fenômeno de retroalimentação (DEMO, 1985).

Essa circularidade sistêmica é a característica metodológica central do sistemismo, pois explica sua capacidade de se manter apesar dos desequilíbrios e dos atritos. Nas ciências sociais, foi a administração que tirou mais proveito da metodologia sistêmica, pois coloca no centro das atenções o problema básico da organizabilidade social (DEMO, 1985). O estudo de organização constitui apenas uma parte do estudo da estrutura social. No qual, a organização em si, prioriza a consecução de metas, e essa consecução de metas é definida como uma relação entre um sistema e as partes relevantes da situação externa em que ele atua ou funciona. Além disso, uma organização consiste em um sistema social, que possui padrão de valores, que define a orientação básica do sistema (organização) em relação a sua operação. Também, há regras normativas que governam os processos adaptativos da organização. Assim, constituindo um sistema, as organizações possuem as exigências básicas adaptativas que se relacionam com a obtenção dos recursos para atingir suas metas ou desempenhar suas funções (PARSONS, 1976).

Os sistemas são divididos em nove tipos, a saber: a) de nível de estruturas; b) dinâmicos simples; c) mecanismos de controle, ou cibernético, ou ainda, termostato; d) sistemas abertos, com uma estrutura que se mantém sozinha; e) genético-social, por exemplo, uma planta; f) animal; g) humano, que é provido de autoconsciência, linguagem e simbolismo; h) sistema social, baseado na organização humana; e i) sistemas transcendentais, que são sistemas supremos e absolutos (KAST; ROSENZWEIG, 1989). Assim, observa-se que os três primeiros sistemas são mecânicos e propiciam a base do conhecimento das ciências físicas. Os sistemas 
do quarto ao sexto escalão referem-se ao sistema biológico (orgânico), e os últimos três relacionam-se com os sistemas humanos e sociais, e são de interesse das ciências sociais (BUCKLEY, 1971; KAST; ROSENZWEIG, 1989).

Baseando-se em sistemas, muitos conceitos apresentam sentido em estudos organizacionais. Inicialmente, a teoria tradicional apresentava a organização através de um sistema fechado, mas a concepção moderna considera a organização como um sistema aberto, que interage com o seu ambiente (KAST; ROSENZWEIG, 1989).

\section{A dialética}

Partindo de Heráclito (536 a.C - 475 a.C), presente nos Neoplatônicos e no Misticismo especulativos do século XIV, além de Hegel, Marx e Engels, a dialética é o objeto de reflexão. A dialética de Georg W. F. Hegel (1770-1831) é idealista, considerando que todo o real é da ordem do pensamento. $\mathrm{O}$ processo dialético apresenta três momentos chamados de tese, antítese e síntese. Porém, Hegel os caracteriza como afirmação, negação e negação da negação. Assim, o processo dialético pelo qual a ideia se realiza na natureza e no espirito assenta-se na contradição. Por outro lado, a doutrina de Karl Marx (1818-1883) é caracterizada pelo materialismo histórico e materialismo dialético, de acordo com Friedrich Engels (1820-1895), e combate o idealismo hegeliano. O materialismo marxista é preocupado com questões sociais e políticas, na forma de crítica ao capitalismo (FOLQUIÉ, 1949).

As concepções autênticas da dialética consistem no tratamento simultâneo aos conjuntos e aos seus elementos constitutivos, ou seja, as totalidades e as partes. De forma que, o que interessa é o movimento entre uns e outros. Além disso, o propósito da dialética enquanto método é que este último é sempre negação, e nega as leis da lógica formal. Também consiste no abalo de toda estabilização aparente da realidade social, e, enquanto método combate o ceticismo e o dogmatismo, enfatiza tensões, oposições, conflitos, lutas, contrários e contraditórios (GURVITCH, 1987).

A lógica pode ser compreendida como formal ou dialética. A lógica dialética nega as leis da lógica formal, assim como o princípio da identidade. Também, examina a interação de elementos opostos, como o sujeito e o objeto. Apesar de o sujeito ser distinto do objeto, ele não pode ser separado dele (LEFEBVRE, 1983). Ademais, a dialética parte dos seguintes pressupostos: a) historicidade; b) processo; c) mutação social; d) conflito social; e e) relatividade social (DEMO, 1985). 
Conforme argumentam Chanlat e Séguin (1992) o desenvolvimento tardio do paradigma crítico se deve principalmente a hegemonia do funcionalismo nas ciências sociais, desinteresse do marxismo em estudos organizacionais, expansão econômica no período pós-guerra, totalitarismo das experiências comunistas e o radicalismo desse paradigma. Em estudos organizacionais, seis concepções compõe o núcleo do paradigma crítico, são eles: a) concepção sociológica da organização; b) concepção histórica; c) concepção dialética da organização; d) concepção desmistificadora; e) concepção "acionalista"; e f) visão emancipadora (SÉGUIN; CHANLAT, 1987).

Ademais, Benson (1983) argumenta que o ponto de vista dialético sobre as organizações trabalham com dois níveis de realidade: a) morfologia: que consiste na forma em que a organização é oficialmente vista e aceita, através de suas escolhas paradigmáticas, definição de ramo de atividade, ideologia e tecnologia, além disso, compreende nos arranjos estruturais, e na forma em que a organização é constituída e as relações entre a organização e o seu ambiente; e b) infraestrutura: que diz respeito a aspectos não racionalizados da ação, ligações profundas, relações de poder e de controle, além da história.

\section{Procedimentos Metodológicos}

Tendo em vista que o objetivo principal deste estudo é analisar sob um ponto de vista epistemológico a Teoria dos Jogos, baseando-se em von Neumann, Morgenstern e Nash, a partir de suas relevantes obras para o campo. Realizou-se uma pesquisa descritiva, a partir de uma abordagem qualitativa, considerando que o emprego desta abordagem busca a análise de aspectos mais profundos e complexos do comportamento humano, fornecendo uma interpretação mais detalhada acerca dos hábitos, atitudes, tendências, entre outros (MAKONI; LAKATOS, 2011).

Primeiramente, foi realizada uma pesquisa bibliográfica, buscando levantar informações e oportunizando maior proximidade com um determinado tema (MICHEL, 2009). Nesse momento, foram levantadas bibliografias referentes aos aspectos epistemológicos e as principais correntes de pensamento científico e filosófico, possibilitando a construção do referencial teórico do estudo. Dessa forma, é possível sintetizar os principais pensadores e suas correntes de pensamento (Figura 1). 
Figura 1 - Principais pensadores e suas correntes.

\begin{tabular}{|c|c|c|c|c|}
\hline $\begin{array}{c}\text { Empirismo/ } \\
\text { Racionalismo }\end{array}$ & $\begin{array}{l}\text { Positivismo/ } \\
\text { Utilitarismo }\end{array}$ & Funcionalismo & Sistemismo & Dialética \\
\hline $\begin{array}{c}\cdot \text { Bacon } \\
\cdot \text { Descartes } \\
\cdot \text { Kant }\end{array}$ & $\begin{array}{c}\text { •Comte } \\
\text { • Popper } \\
\text { •Círculo de } \\
\text { Viena } \\
\text { •Bentham }\end{array}$ & $\begin{array}{c}\text {-Durkheim } \\
\text { - Malinowski } \\
\text { - Radcliffe- } \\
\text { Brown }\end{array}$ & $\begin{array}{l}\text {-Parsons } \\
\text { - Buckley } \\
\text { • Kast e } \\
\text { Rosenzweig }\end{array}$ & $\begin{array}{c}\text { - Marx } \\
\text { - Gurvitch } \\
\text { - Chanlat e } \\
\text { Séguin } \\
\text { - Benson }\end{array}$ \\
\hline
\end{tabular}

Fonte: elaboração própria.

A partir da elaboração da base teórica resultante do levantamento bibliográfico sobre epistemologia, foi possível avançar para a próxima etapa, que consiste em uma análise documental sob a ótica da epistemologia nas obras de John von Neumann, Oskar Morgenstern e John Forbes Nash. A análise documental possibilita uma nova interpretação de obras e documentos que já foram processados (GIL, 2008). Diante disso, foram selecionadas as obras de maior relevância na temática teoria dos jogos. Conforme a figura 2.

Figura 2 - Obras selecionadas para a análise.

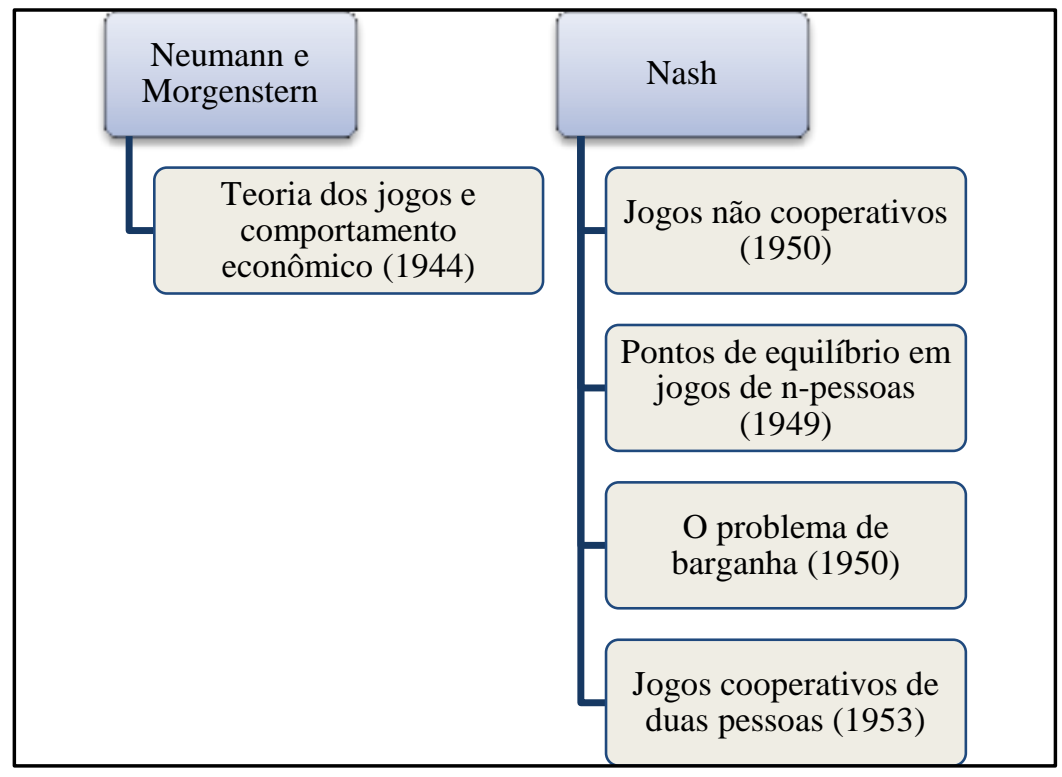

Fonte: elaboração própria.

Diante do exposto, foi possível estabelecer uma análise epistemológica sobre os trabalhos selecionados, os principais resultados da análise são delineados na seção 4 . 


\section{ANÁLISE EPISTEMOLÓGICA}

A partir do levantamento teórico acerca de epistemologia, o próximo passo da realização do trabalho consistiu na análise epistemológica das obras relacionadas à teoria dos jogos, buscando estabelecer suas filiações e enfatizar as características dos autores, tais como, nacionalidade, filiação institucional, influências, e demais aspectos relevantes.

\section{As raízes da Teoria dos Jogos}

Oriunda da matemática, a teoria dos jogos desenvolveu-se no Século XX, após a $1^{\mathrm{a}}$ Guerra Mundial. Centra-se no estudo do conflito, ou seja, quando atividades incompatíveis ocorrem, podendo se dar entre pessoas, grupos ou nações. O conceito de conflito nesse contexto refere-se a uma situação em que duas partes necessitam desenvolver estratégias que maximizem seus ganhos, com base em regras pré-estabelecidas (ALMEIDA, 2003).

A Universidade de Princeton foi de suma importância ao desenvolvimento da teoria dos jogos, tendo em vista que contava em seu quadro de professores von Neumann, Einstein, Gödel e Oppenheimer, e muitos outros físicos e matemáticos destacados. Entre os anos de 1940 e 1960, a universidade caracterizou-se como um grande centro de matemática e física. Nessa época, a matemática era vista como a chave de um mundo melhor no pós-guerra. Além da Universidade de Princeton, destaca-se a RAND, criada em 1940 pela Força Aérea dos Estados Unidos para o desenvolvimento de novas estratégias militares. Dentre as suas linhas de pesquisa, enquadrava-se a teoria dos jogos com finalidades militares, sendo de fundamental importância para o desenvolvimento estratégico na $2^{a}$ Guerra Mundial (ALMEIDA, 2003).

Em 1928, Von Neumann publicou um artigo demonstrando que jogos finitos de soma zero com duas pessoas possuem uma solução. Essa demonstração original era muito complicada de se acompanhar, e, em 1937 publicou um artigo com uma nova demonstração baseada no teorema do ponto fixo de Brouwer. Von Neumann trabalhava em diferentes áreas da ciência, mas na economia, juntamente com Morgenstern publicou o clássico livro "Teoria de jogos e comportamento econômico" em 1944. Marco da invasão da matemática aplicada na economia (SARTINI et al., 2004).

Outro autor de destaque da teoria dos jogos foi Nash, que rompeu com o paradigma econômico ao qual a teoria de von Neumann se baseava (ALMEIDA, 2003). Em 1950 o autor publicou artigos importantes sobre a teoria de jogos não cooperativos e teoria de barganha. Além disso, provou a existência de um equilíbrio de estratégias mistas em jogos não 
cooperativos, chamado de Equilíbrio de Nash, e sugeriu uma abordagem para o estudo de jogos cooperativos dada pela redução a forma não cooperativa ${ }^{3}$. Também, desenvolveu a teoria de barganha e provou a possibilidade de solução do problema de barganha de $\operatorname{Nash}^{4}$ (SARTINI et al., 2004).

Nash, juntamente com Harsanyi e Selten, contribuíram para a expansão da utilização da teoria dos jogos para um número maior de situações do que se de um lado um jogador ganha, o outro perde. O equilíbrio de Nash aplica-se a jogos de soma não zero, onde cada jogador adota a estratégia que é a melhor resposta diante das estratégias dos outros jogadores, ou seja, diante das possibilidades de jogo dos seus concorrentes, em que os jogadores não teriam melhores resultados mudando a jogada (SOUSA, 2005).

Ainda que tenha sido criada nos anos de 1940, a teoria dos jogos por muitos anos sofreu o "obscurantismo" da matemática. Descrédito que findou em 1994, ano em que Nash conquistou o Prêmio Nobel de Economia pelos trabalhos em teoria dos jogos. Apesar de ninguém refutar a teoria atualmente, no passado ela não era reconhecida, pois buscava modelar comportamentos através da matemática. Sendo desacreditada por matemáticos, pois se desviava da matemática dita como pura, e pelos cientistas sociais, que não admitiam a possibilidade de se estudar o comportamento com cálculos (MARINHO, 2011).

Um jogo em si, consiste em um conjunto de regras e um conjunto de resultados. As regras apresentam a realidade e a situação-problema, limitando as ações dos jogadores. Dessa forma, os jogadores tomam decisões racionais e maximizadoras, buscando resultados. Dentro do conjunto de regras podem ser elencados os seguintes elementos: a) os jogadores, que consistem em agentes econômicos tomadores de decisão, espera-se que sejam racionais, que possuam preferências e que busquem maximizar sua satisfação; b) um conjunto de estratégias e ações possíveis de cada jogador, ou seja, conjunto de ações a ser executado; c) um conjunto de informações disponíveis aos jogadores, e como elas se apresentam; e d) um conjunto de resultados possíveis (payoffs), que consistem nas formas em que os resultados das ações e estratégias podem tomar (DIAS, 2004).

No que se refere ao número de jogadores, o autor supracitado argumenta que é possível identificar diferentes formas ou tipos de jogos, dependendo das características apresentadas, além disso, os jogos podem envolver um ou mais jogadores. No entanto, em se tratando das

\footnotetext{
${ }^{3}$ A partir das publicações "Equilibrium points in n-Person games" e "Non-cooperative games".

${ }^{4}$ De acordo com os artigos "The bargaining problem" e "Two person cooperative games".
} 
informações disponíveis, os jogos podem apresentar: a) informação completa, no qual os jogadores possuem todas as informações necessárias para a sua tomada de decisão; b) informação incompleta, em que algumas informações não estão disponíveis; c) informação perfeita ou sequencial, que consistem em jogadores que atuam de maneira sequencial; d) informação imperfeita ou jogos simultâneos, a qual consiste numa forma de jogo em que os jogadores atuam simultaneamente; e) forma de jogos cooperativos, que permite que ocorram acordos entre os jogadores; f) forma de jogos não cooperativos, no qual os acordos não são permitidos ou possíveis; g) forma de jogos de soma constante, dessa forma, independente das ações dos jogadores, a soma dos resultados é constante; h) forma de jogos de soma zero, que consiste em um jogo de soma constante, porém, o ganho de um jogador equivale a perda do outro; e i) forma de um jogo de soma variável, a qual a soma dos resultados é incerta.

Um exemplo de fácil entendimento desses jogos é o Dilema dos Prisioneiros, elaborado por John Raws, que consiste em uma narrativa em que dois suspeitos são presos, mas a polícia não possui provas suficientes para a condenação, assim, oferece um acordo aos prisioneiros em salas separadas, o acordo consiste em: 1) caso um dos prisioneiros confesse, e o outro se mantenha em silêncio, o prisioneiro que confessou sai livre, porém o outro é punido em 10 anos; 2) caso ambos não confessem, os dois serão condenados a 1 ano; e 3) caso ambos confessem, cada um é condenado a 5 anos de detenção. Dessa forma, o dilema é um jogo de duas pessoas, não cooperativo e de soma não zero, ou seja, o que um jogador perde, o outro não necessariamente ganha. Uma decisão que se tornaria vantajosa aos dois lados é o de cooperação, ou seja, que os dois prisioneiros não confessem, porém, não havendo a possibilidade de um confiar no outro, através de um código comum, é difícil que a cooperação aconteça, pois os prisioneiros não sabem se o promotor apresentou as mesmas condições ao outro (RAWS, 1971).

Diante do exposto, vale ressaltar que a teoria dos jogos apresenta diferentes formas de resolução dos problemas. Os conceitos mais conhecidos de tomada de decisão, ou de solução consistem em: a) conceito de estratégias dominantes: uma estratégia é tida como dominante quando é a melhor opção ao jogador, independentemente da ação do adversário; b) estratégia maxmin: os jogadores são prudentes, escolhendo a estratégia maxmin, assim, cada jogador procura maximizar o mínimo que ele pode assegurar a si mesmo, independendo da ação do outro, garantindo o ganho mínimo para cada membro do jogo; c) equilíbrio de Nash: consiste numa combinação de estratégias em que nenhum dos jogadores se arrepende, pois, os jogadores 
não podem melhorar a sua situação de forma unilateral. Ou seja, indica que cada jogador escolheu a melhor estratégia, independente do outro (DIAS, 2004).

\section{Von Neumann e Morgenstern}

John von Neumann nasceu em Budapeste - Hungria, em 28 de dezembro de 1903. Como seu pai era banqueiro, foi possível que John crescesse em um ambiente culto, e desenvolvesse suas habilidades em línguas e na matemática. Por volta de 1919, a família von Neumann fugiu para a Áustria, durante o governo comunista de Béla Kun. Devido ao grande interesse de John em matemática, o jovem queria estudá-la, porém, seu pai não aprovou, pois preferia ver o filho seguir o seu caminho nas finanças. Dessa forma, John acabou indo cursar química nas universidades de Berlim e de Budapeste. Em 1925, John obteve o diploma de engenheiro químico pela Swiss Federal Institute os Tecnology, em Zurique. Porém, não abandonou a matemática, recebendo seu $\mathrm{PhD}$, na Universidade de Budapeste em 1926. Sua carreira acadêmica começou na Universidade de Berlim. Posteriormente mudou-se para a Universidade de Hamburgo, onde permaneceu durante 1929 e 1930. Realizou seu pósdoutorado na Universidade de Götingen, sendo aluno do matemático David Hilbert (LEONARD, 1992).

Mais tarde, a partir do convite para ministrar um curso de teoria quântica na Universidade de Princeton, John obteve uma posição permanente na universidade. Nessas alturas, o matemático já havia se casado com Mariette Koevese, e se convertido ao catolicismo. Em 1933, com o regime nazista na Alemanha, ele largou os vínculos institucionais que ainda possuía no país. Logo que o Instituto de Estudos Avançados de Princeton (IEA) foi criado, John foi nomeado integrante, marcando o final da curta carreira docente dele (LEONARD, 1992).

Von Neumann participou de diversos projetos de pesquisa, nos anos 1920 ele integrou o grupo de Hilbert que objetivava colocar a matemática em alicerces mais sólidos através da formalização mais rigorosa de diferentes campos da matemática. Ainda nesse período, o matemático trabalhou com a teoria quântica e publicou um trabalho sobre indeterminismo. Observa-se que von Neumann sofreu forte influência de Hilbert, tendo em vista que as áreas de interesse dele se encaixavam com o que Hilbert se dedicava. Ademais, assim como Hilbert, von Neumann defendia que a matemática era muito importante, pois é ela que estabelece certos padrões de objetividade, de verdade, independente de questões emocionais e morais (LEONARD, 1992). 
Foi só no final dos anos 1930 que o matemático passou a trabalhar com a teoria dos jogos, a partir do incentivo de Morgenstern. Nessa época a teoria dos jogos começou a ser utilizada na estratégia militar dentro da Rand Corporation, empresa de pesquisas da Força Aérea dos Estados Unidos. E nos anos 1940 incluiu em seus estudos a computação eletrônica. Tendo participado do desenvolvimento e aprimoramento do computador eletrônico ENIAC, como consultor da IBM. Em 1943, Von Neumann foi convidado por Julius Robert Oppenheimer para integrar o Projeto Manhattan. Trabalhando nos cálculos sobre a implosão da bomba atômica. Por volta de 1950 largou os trabalhos na Rand para se dedicar a Comissão de Energia Atômica, mas logo adoeceu, falecendo em 1957, aos 53 anos, vítima de um tumor cerebral (LEONARD, 1992).

Oskar Morgenstern nasceu em Görlitz, Alemanha em 1902. Com 12 anos, mudou-se para a Áustria, depois da falência da família. Realizou seus estudos na Universidade de Viena, onde concluiu seu doutorado em ciência política em 1925. Por ser bolsista da Rockfeller, passou os anos seguintes no exterior e tornou-se professor da Universidade de Viena em seguida. Em 1931 tornou-se diretor do Instituto Austríaco de Pesquisa dos Ciclos Econômicos. E, enquanto residiu em Viena, trabalhou com ciclos econômicos e a crítica metodológica da economia, tratando de problemas como a relação entre o tempo e a previsão na teoria do equilíbrio geral. No fim dos anos 1930, ao visitar os Estados Unidos, Morgenstern conseguiu uma colocação temporária na Universidade de Princeton, mais tarde, fixou-se no departamento de economia. Em 1970 aposentou-se naquela universidade, indo para a Universidade Nova York, onde ficou até seu falecimento, em 1976 (LEONARD, 1992).

Conforme argumenta Rellstab (1992), em 1938 Von Neumann e Morgenstern se encontraram pela primeira vez em Princeton. Depois de seguidos encontros, em 1940 os pesquisadores começam a discutir efetivamente sobre comportamento, jogos, matemática, etc. Já em 1941, os dois começam a escrever um artigo em conjunto sobre jogos. Essa intensa colaboração resultou nos capítulos iniciais de "Teoria de jogos e comportamento econômico", publicado em 1944 pela Princeton University Press, financiado por John D. Rockfeller.

O contexto histórico em que a obra foi desenvolvida foi marcado por um período entreguerras, compreendido entre a Primeira e a Segunda Guerra Mundial, e pela Grande Depressão. Apesar de já consistir na maior economia do mundo, os Estados Unidos enfrentou uma severa crise em 1913. Somente no fim dos anos de 1920 que o comércio mundial começou a se recuperar, porém, essa recuperação foi abalada pela Grande Depressão de 1929, atingindo 
todos os países que dependiam da exportação de produtos primários, nem mesmo países mais industrializados escaparam (SOUSA, 2005).

A teoria econômica da época não deu conta dos fatos, e a partir dela, não havia o que se fazer, a não ser esperar que os mercados se autoajustassem. Tal instabilidade solapou a Lei de Say, pedra angular da teoria neoclássica, a velha economia liberal e seu sistema mundial de comércio multilateral. A redução do desemprego passou a ser o principal desafio da política econômica nos países. A teoria econômica acabou se dividindo em dois grandes campos, a macroeconomia e a microeconomia. Atualmente, essa última é ligada à teoria dos jogos. Porém, a microeconomia fundamentou-se nos pressupostos da teoria neoclássica, alicerçado na tese dos mercados em equilíbrio, mas a macroeconomia keynesiana não concordava com tal pressuposto (SOUSA, 2005).

Foi nesse contexto que a teoria dos jogos ganhou maior atenção, além de uma formalização mais rigorosa. Leonard (1992) afirma que à medida que von Neumann desenvolvia suas ideias sobre a teoria dos jogos, ele escutava as fortes críticas de Morgenstern sobre a teoria econômica. Enquanto o primeiro apresentava forte rigor matemático, o segundo queria desenvolver uma teoria do comportamento social. Para eles, uma teoria econômica exitosa e capaz de fazer previsões, deveria levar em consideração que os indivíduos são tomadores de decisões, e que essas decisões dependem dos demais indivíduos. Ademais, os indivíduos apresentariam informações incompletas dos fatos e agiriam através da racionalidade subjetiva. Em 1941 os pesquisadores resolveram reunir os seus esforços, o que resultou no livro. Somente a partir disso que a teoria dos jogos passou a ser utilizada como ferramenta econômica.

Mirowski (1992) defende que von Neumann acreditava que o comportamento estocástico comum ao mundo natural e ao social eram formados por padrões probabilísticos. Ademais, acreditava que por trás dos fenômenos da interação humana havia regras impessoais. Assim a teoria dos jogos, próxima a teoria neoclássica, reduziria o comportamento humano a aspectos passíveis de formalização.

Conforme argumenta Sousa (2005) a aplicação da teoria dos jogos na ciência econômica é parte importante do esforço de formalização matemática da economia, tendo a física como modelo. Pois, consistiu numa tentativa de levar às ciências sociais os padrões metodológicos das ciências da natureza sujeitas a modelagem matemática. Cabe destacar que o ponto de partida do uso da matemática em economia refere-se a Cournot. Após concluir seu doutorado 
em 1829 ele começou a analisar o papel da matemática aplicada em ciencias sociais. Seus trabalhos apresentaram relações como demanda, oferta e preços através de funções matemáticas. Apesar disso, a ideia principal de sua obra, que permanece até hoje em microeconomia é a teoria do duopólio (SOUSA, 2005).

Voltando a von Neumann e Morgenstern, os autores argumentam em sua obra que na física as vezes surgem teorias buscando estabelecer bases para um sistema universal, porém, não haveria progresso se os pesquisadores se concentrassem no estabelecimento de grandes sistemas universais. Não se aplicando a economia, dada como uma área muito menos compreendida, e em um estágio anterior se comparada com a física. Dessa forma, a economia necessita de uma teoria micro, que busque resolver os problemas individuais, para posteriormente partir-se para um sistema geral. Os autores acreditavam que para o entendimento dos problemas econômicos era necessária uma nova matemática, diferente das formulações de Walras sobre os equilíbrios dos mercados. Assim, a matemática dos jogos ao ser aplicada no comportamento humano era fundamental para aos processos econômicos (SOUSA, 2005).

“[...] fiquemos cientes de que atualmente não existe um sistema universal de teoria econômica e que, se alguém desenvolver, muito provavelmente não será durante a nossa vida. A razão para isso é simplesmente isso. A economia é uma ciência muito difícil para permitir sua construção rapidamente, especialmente tendo em vista o conhecimento muito limitado e a descrição imperfeita dos fatos com os quais os economistas estão lidando. [...] temos que notar que as diferenças em questões científicas tornam necessário o uso de métodos variáveis que possam ser posteriormente descartados se forem oferecidos melhores. Isso tem uma implicação dupla. Em alguns ramos da economia, o trabalho mais frutuoso pode ser o de descrição cuidadosa e paciente; [...] em outros, pode ser possível desenvolver uma teoria de forma rigorosa, e para esse fim, pode ser necessário o uso de matemática." (VON NEUMANN; MORGENSTERN, 1944).

Conforme observado e anteriormente elencado, os autores buscam fortemente a utilização da matemática em economia, e ainda, destacam a necessidade de rigor metodológico, e de como a matemática supriria essa necessidade, pensamento característico do positivismo. E ainda argumentam:

A matemática realmente foi usada na teoria econômica, talvez até de forma exagerada. Em qualquer caso, seu uso não tem sido bem sucedido. Isso é contrário ao que se observa em outras ciências. [...] Não é que exista uma razão fundamental pela qual a matemática não deve ser usada em economia. Os argumentos voltam-se ao elemento humano, dos fatores psicológicos, etc., ou porque - supostamente - não há nenhuma medida de fatores importantes. [...] Quase todas essas objeções foram feitas, ou podem ter sido feitas, há séculos em campos onde a matemática agora é o principal instrumento de análise. Existem muitos cientistas sociais que se opõem ao desenho de tais paralelos em vários motivos, entre os quais geralmente é encontrada a afirmação 
de que a teoria econômica não pode ser modelada como a física, uma vez que é uma ciência do fenômeno social, humano, tem que levar em consideração a psicologia, etc. Essas declarações são pelo menos prematuras. É sem dúvida razoável descobrir o que levou ao progresso em outras ciências e investigar se a aplicação dos mesmos princípios não pode levar ao progresso em economia também.

[...] é essencial perceber que os economistas não podem esperar um destino mais fácil do que o que aconteceu aos cientistas em outras disciplinas. [...] e tentar estabelecer teorias que explicam e que realmente se adequam a padrões científicos rigorosos. Nós podemos ter confiança suficiente para que, a partir daí, a ciência da economia cresça ainda mais.” (VON NEUMANN; MORGENSTERN, 1944).

O discurso dos autores está na importância da matemática e da quantificação do comportamento humano. Além disso, ressaltam que em economia, assim como já ocorrido nas outras ciências, o desenvolvimento se dará através da inserção da matemática e dos padrões científicos rigorosos. Segundo Giddens (1995), o positivismo caracteriza-se de acordo com as seguintes perspectivas: a tese de que a realidade consiste em impressões sensíveis; a aversão a metafísica (sofismo ou ilusão); o apelo a filosofia da ciência como método de análise devidamente separada das descobertas da ciência; a dualidade entre fato e valor; e a noção da unidade da ciência que afirma o compartilhamento de uma lógica metodológica comum entre as ciências naturais e sociais. Esse último aspecto é fortemente observado na obra de von Neumann e Morgenstern.

Ademais, a ideia central da obra está voltada ao comportamento racional dos seres humanos, os quais buscam maximizar a sua utilidade. Conforme o fragmento abaixo:

\footnotetext{
"Devemos, portanto, assumir que o objetivo de todos os participantes no sistema econômico, consumidores e empresários, é o dinheiro, ou de forma equivalente uma mercadoria monetária.” (VON NEUMANN; MORGENSTERN, 1944).
}

A teoria dos jogos se apoia no princípio da racionalidade instrumental onde os jogadores buscam os melhores resultados para si ou para o grupo. Parte-se do pressuposto de que os jogadores são dotados de uma racionalidade perfeita, sendo esse aspecto o principal alvo de críticas (ABBADE, 2009). As teorias da escolha racional são definidas como positivas, pois os jogadores sociais estariam interessados na maximização da riqueza (FEREJOHN; PASQUINO, 2001).

Abbade (2009) argumenta que é inegável a influência da racionalidade em teorias administrativas (administração científica, escola clássica, escola das relações humanas, estruturalismo, teoria dos sistemas e similares), centradas na racionalidade instrumental e análise da eficiência administrativa. Tal corrente talvez foi a que mais influenciou a teoria dos jogos, a racionalidade instrumental, caracterizada pelo cálculo utilitário de consequências. 
Dessa forma, a teoria dos jogos é utilizada em busca da maximização do ganho, estando a racionalidade intimamente relacionada com os interesses dos jogadores. No mundo capitalista em que vivemos é comum que as pessoas sejam guiadas pela racionalidade formal (cálculo utilitário de consequências). Spink (2002) defende que a ideia de racionalidade se baseia na filosofia liberal, e em seu caráter mais específico, o utilitarismo. O utilitarismo foi desenvolvido por Bentham, o qual acreditava ter elaborado uma ciência do bem-estar ou da felicidade humana, expressa matematicamente, e que fosse um dia tão exata quanto a física (HUNT, 2005).

No teorema minimax, busca-se obter o maior ganho e a menor perda possível ao jogador, este, orientado pela racionalidade instrumental. Conforme argumenta Poundstone (1992), os autores apresentaram a teoria dos jogos como uma ferramenta matemática para a economia. Assim, os conflitos econômicos poderiam ser analisados como jogos. A pedra fundamental da teoria seria o teorema minimax, von Neumann acreditava que a teoria poderia ser desenvolvida para outros jogos, como jogos com mais de dois jogadores e aqueles em que os concorrentes tivessem interesses em comum. Podendo, a teoria dos jogos, abranger todos os tipos de relações humanas.

$\mathrm{O}$ aspecto que mais gerou críticas, possivelmente foi a forma em que a racionalidade dos jogadores é defendida. Esses princípios racionais vão de encontro com a teoria da racionalidade limitada de Simon, pois defende-se que os participantes do jogo preveem e antecipam as decisões e escolhas estratégicas dos outros jogadores, ou seja, afirma-se que o jogador possui racionalidade perfeita, e em consequência disso, informação perfeita (ABBADE, 2009).

Ademais, Munck (2000) reconhece também o aspecto positivo dos modelos da teoria dos jogos devido as soluções através da lógica dedutiva inerente aos modelos. Dentre os pesquisadores há aqueles que se dedicam a construção de modelos e aqueles que se interessam com problemas reais. Conforme argumenta Abbade (2009) a aplicação da teoria pode ser de grande relevância para os campos de estudo onde o elemento social é influenciador. Situações que exigem análise das alternativas de comportamento e tomada de decisões.

\section{John Forbes Nash Jr.}

Von Neumann não foi a única personalidade controversa de Princeton nos anos 19401950. Na época, havia outro John na universidade, também arrogante e bem apessoado. Esse 
cidadão era John Forbes Nash Jr., um jovem doutorando do departamento de matemática (MARINHO, 2011). Nash nasceu em Bluefield, West Virginia, nos Estados Unidos, em 1928. Durante a infância era considerado antissocial e introvertido. Durante a adolescência interessou-se em matemática e ingressou na Universidade de Carnegie Mellon. Seu desempenho na graduação foi tão brilhante que lhe rendeu o título de mestre (CAMPOS; CARDOSO, 2015). Conforme destacam Kuhn e Nasar (2008), seu orientador escreveu uma carta de recomendação para Nash prosseguir seus estudos, a carta era composta apenas pela seguinte frase: "Este homem é um gênio".

O jovem recebeu ofertas de bolsas nas Universidades de Harvard, Princeton, entre outras. Porém, optou pela Universidade de Princeton, pela proximidade de casa. Concluiu o doutorado aos 22 anos. Como tinha uma personalidade reclusa, Nash não assistia as aulas e estudava sozinho. Em sua tese "Jogos não cooperativos" escrita em 1950, com apenas 28 páginas, ele estabeleceu as propriedades do Equilíbrio de Nash. Tal conceito, relacionado aos jogos não cooperativos revolucionou os estudos de estratégia política e econômica. Rendendolhe em 1994 o prêmio de Ciências Econômicas em Memória de Alfred Nobel. Após a conclusão de seu doutorado, ele lecionou em Princeton durante um ano, após tornou-se professor de matemática do Massachusetts Institute of Technology (MIT), permanecendo até 1959. Durante sua permanência no MIT, suas pesquisas foram focadas em geometria diferencial e equações diferenciais parciais não lineares (CAMPOS; CARDOSO, 2015).

Nos anos 1950, Nash publicou quatro importantes artigos para a teoria dos jogos não cooperativos e para a teoria de barganha. Em "Pontos de equilíbrio em jogos de n-pessoas" e "Jogos não cooperativos" ele provou a existência de um equilíbrio de estratégias mistas para os jogos não cooperativos, conhecido como Equilíbrio de Nash, além de sugerir uma abordagem de estudo de jogos cooperativos para a forma não cooperativa. Ademais, nos artigos "O problema de barganha" e "Jogos cooperativos de duas pessoas" a teoria de barganha foi criada, além disso, foi provada a existência de solução para o problema da barganha de Nash (SARTINI et. al, 2004).

Nash casou-se em 1957 com Alicia, uma aluna do MIT, com a qual teve um filho. A partir de 1958, ele foi diagnosticado com esquizofrenia paranoica, chegando a ser internado por meses. Durante a década de 1950, também se dedicou a criptografia, propondo a agência de segurança nacional dos Estados Unidos um projeto de um dispositivo de codificação e decodificação. Trabalho o qual antecipava os conceitos de criptografia computacional moderna. 
Devido ao estresse pelos distúrbios mentais de Nash, o casal acabou se divorciando em 1963. No entanto, depois de sua última internação hospitalar em 1970, o casal voltou a viver juntos (CAMPOS; CARDOSO, 2015).

Na sequência, à medida que Nash se recuperava, ele retornou a trabalhar em Princeton, lecionando matemática. Além disso, em 2001, Alicia e Nash voltaram-se a se casar. Em 2014 o matemático esteve no Brasil para ministrar uma palestra no International Workshop on Game Theory and Economic Applications of the Game Theory Society, realizado na Universidade de São Paulo. Sua vida foi biografada por Sylvia Nasar, e mostrada em diversos documentários (CAMPOS; CARDOSO, 2015). Além disso, sua vida foi retratada no filme Uma Mente Brilhante (2001), vencedor de quatro Oscar. Em 2015, Nash e Alicia faleceram vítimas de um acidente de trânsito.

Em seus trabalhos, Nash partiu do ponto em que von Neumann e Morgenstern haviam parado em sua teoria. Apesar de ter se afastado por anos devido a sua saúde, Nash e a teoria dos jogos se tornaram indissociáveis. Posteriormente a defesa de seu doutorado, trabalhou também na RAND Corporation, onde von Neumann também trabalhara (MARINHO, 2011).

Aperfeiçoando a teoria dos jogos, Nash abordou de forma inovadora a maneira com que dois agentes racionais interagiam numa barganha. De acordo com o matemático, o conceito de equilíbrio depende da disposição recíproca das diferentes partes, no qual nenhum participante poderia melhorar sua situação optando por outra alternativa. Assim, independendo do número de jogadores, o jogo vai ter pelo menos um ponto de equilíbrio (SOUZA, 2003).

Através disso, juntamente com o teorema minimax, o equilíbrio de Nash tornou-se um dos alicerces fundamentais da teoria dos jogos, permitindo que os jogos não cooperativos fossem tratados. A precisão das provas matemáticas de von Neumann e Nash, apesar de sólidas, levaram os pesquisadores a obter contraexemplos e elaborarem experimentos que consolidassem a teoria dos jogos (BARROS, 2005). Conforme argumenta Xavier (2013), duas principais hipóteses fornecem as bases para a teoria dos jogos não cooperativos de Nash. A primeira refere-se a maximização, postulado fundamental da racionalidade. A segunda é a hipótese de consistência, refere-se as expectativas corretas dos agentes em relação ao outro, implicando que o padrão de escolhas otimizadoras individuais constitui um equilíbrio de Nash.

Assim como na obra de von Neumann e Morgenstern, em que o jogador era orientado por uma racionalidade instrumental. Nas obras de Nash, em jogos não cooperativos também observa-se aspectos de uma racionalidade instrumental, tendo em vista que os jogadores 
buscam uma melhor solução para o grupo, em detrimento do individual, porém, alguns aspectos de uma racionalidade substantiva podem ser observados, mas o que impera é a racionalidade instrumental (ABBADE, 2009).

\section{CONSIDERAÇÕES FINAIS}

O presente estudo teve por objetivo analisar sob um ponto de vista epistemológico a teoria dos jogos, baseando-se em von Neumann, Morgenstern e Nash, a partir de suas relevantes obras para o campo, "Teoria de jogos e comportamento econômico" de Von Neumann e Morgestern, e "Pontos de equilíbrio em jogos de n-pessoas", "Jogos não cooperativos", "O problema de barganha" e "Jogos cooperativos de duas pessoas" sob autoria de Nash.

Diante disso, foi possível observar que a teoria dos jogos aborda matematicamente o processo de tomada de decisão de agentes, cujo objetivo principal é a maximização da utilidade dos jogadores, que se pautam em decisões racionais. Dessa forma, em seus conceitos é possível identificar, sobremaneira, características do utilitarismo e do positivismo.

Cabe mencionar que esses paradigmas verificados nas obras de Nash, von Neumann e Morgenstern, ainda exercem grande influência na geração do conhecimento nas ciências sociais, assim como nas demais áreas de conhecimento. Além disso, muitos dos pesquisadores atuais foram formados sobre essa base epistemológica, dificultando o desenvolvimento de estudos baseados no paradigma emergente. Apesar disso, mais recentemente tem-se observado movimentos no sentido da transição a um novo paradigma em ciências sociais.

\section{REFERÊNCIAS}

ABBADE, E. B. Aplicação da teoria dos jogos na análise de alianças estratégicas. Revista de Administração, v. 7, n. 3, p. 24-45, 2009.

ALMEIDA, F. P. L. A teoria dos jogos: uma fundamentação teórica dos métodos de resolução de disputa. Estudos em arbitragem, mediação e negociação, p. 175, 2003. Disponível em: http://www.arcos.org.br/livros/estudos-de-arbitragem-mediacao-e-negociacao-vol2/terceiraparte-artigo-dos-pesquisadores/a-teoria-dos-jogos-uma-fundamentacao-teorica-dos-metodos-deresolucao-de-disputa>. Acesso em: 17 dez. 2017.

ANDRADE, M. A. R.; DAMÁZIO, D.; BARRETO, M. Z. TEORIA DOS JOGOS, UMA FERRAMENTA PARA A ESTRATÉGIA DAS ORGANIZAÇÕES. In: Simpósio de Excelência em Gestão e Tecnologia - SEGeT, 13, 2016, Resende. Anais... Resende: AEDB, 2016. 
BACON, F. Novum organum ou verdadeiras indicações acerca da interpretação da natureza. Tradução e notas J. A. R. de Andrade. São Paulo: Abril Cultural, 1979.

BARROS, S. A. M. Modelos de duopólio com incertezas. Dissertação de Mestrado (Faculdade de Ciências da Universidade do Porto), 2005. Disponível em: < https://repositorioaberto.up.pt/handle/10216/64094>. Acesso em: 20 dez. 2017.

BENTHAM, J. Uma introdução aos princípios da moral e da legislação. Coleção os pensadores. São Paulo: Abril Cultural, 1979.

CHANLAT, J. F.; SÉGUIN, F. L'analyse des organisations, une anthologie sociologique. Quebec, Gaëtan Morin, tome 1, p. 37-38, 1992.

CHEVALLIER, J; LOSCHAK, D. A ciência administrativa. Mem Martins: Europa-America, 1980.

DA SILVA, Alini et al. UTILIZAÇÃO DA ESTRATÉGIA PURA DA TEORIA DOS JOGOS PARA DETERMINAÇÃO DO PREÇO DE VENDA. Revista Eletrônica de Estratégia \& Negócios, v. 8, n. 3, p. 187-204, 2016.

DEMO, P. Metodologia científica em ciências sociais. São Paulo: Atlas, 1985.

DIAS, H. P. Teoria dos Jogos. Global Manager / Faculdade da Serra Gaúcha - v. 4, n. 6 Caxias do Sul: FSG, 2004.

DORTIER, J. F. Le cercle de Vienne et le nouvel sprit scientifique. In: Sciences Humaines, hors-série, septembre 2000.

DURKHEIM, É. As regras do método sociológico (cap. primeiro); Da divisão do trabalho social (livro I, cap. 1), in Durkheim, coleção os pensadores. São Paulo: Abril Cultural, 1978.

EVANS-PRITCHARD, E. Desenvolvimento teórico posterior, in Antropologia social. Lisboa: Edições 70, 1972.

FEREJOHN, J.; PASQUINO, P. A teoria da escolha racional na ciência política: conceitos de racionalidade em teoria política. Revista Brasileira de Ciências Sociais, RBCS Vol. 16 no 45 fevereiro/2001. Disponível em: <

http://www.scielo.br/scielo.php?script=sci_arttext\&pid=S0102-69092001000100001>. Acesso em: 20 jan. 2018.

FIGUEIREDO, R. S. Teoria dos jogos: conceitos, formalização matemática e aplicação à distribuição de custo conjunto. Gestão \& Produção, v. 1, n. 3, p. 273-289, 1994.

FREITAS, K. M.; ALVES, J. N.; JUNGES, V. C. Teoria dos Jogos: uma análise exploratória. In: Seminário de Ensino Pesquisa e Extensão, 21, 2016, Cruz Alta. Anais... Cruz Alta: Unicruz, 2016. Disponível em: <https://home.unicruz.edu.br/seminario/anais/anais-

2016/XXI\%20Semin\%C3\%A1rio\%20Interinstitucional\%202016\%20-

\%20Anais/Gradua\%C3\%A7\%C3\%A3o\%20-\%20RESUMO $\% 20$ EXPANDIDO $\% 20-$

$\%$ 20Sociais $\% 20 \mathrm{e} \% 20$ Humanidades/TEORIA\%20DOS\%20JOGOS\%20-

\%20UMA\%20AN\%C3\%81LISE\%20EXPLORAT\%C3\%93RIA.pdf>. Acesso em: 20 jan. 2018.

FOULQUIÉ, P. A dialética. 3 ed. Press Universitaires de France, 1949. 
GIDDENS, A. Política, sociologia e teoria social: encontros com o pensamento social clássico e contemporâneo. Trad. Cibele Saliba Rizek. São Paulo: Fundação Editora da Unesp, 1998.

GIL, A. C. Como elaborar projetos de pesquisa. 4. ed. São Paulo: Atlas, 2008.

GURVITCH, G. Dialética e sociologia. Tradução de Maria Stela Gonçalves. São Paulo: Vértice, 1987.

HUNT, E. K. História do pensamento econômico. Campus, 2005.

JAPIASSU, H. Introdução ao Pensamento Epistemológico. 6 ed. São Paulo: Francisco Alves, 1991.

KANT, I. Crítica da Razão Pura. Tradução e notas de Fernando Costa Mattos. 4 ed. Petrópolis: Vozes. 2015.

KUHN H. W.; NASAR, S. (eds.). The Essential John Nash. Princeton: Princeton University Press, 2008. Disponível em: https://books.google.com.br/books?hl=pt-

$\mathrm{BR} \& \mathrm{lr}=\& \mathrm{id}=\mathrm{XZYvDAAAQBAJ} \& o \mathrm{i}=\mathrm{fnd} \& \mathrm{pg}=\mathrm{PP} 1 \& \mathrm{dq}=\mathrm{The}+$ Essential $+\mathrm{John}+$ Nash\&ots=Prsp FUSSL5\&sig=Qrg2q-

FdKBSyWcCtSobfL0f4FjA\#v=onepage \&q=The $\% 20$ Essential $\% 20 J o h n \% 20$ Nash $\& f=$ false.

Acesso em: 15 jan. 2018.

LEFEBVRE, H. Lógica formal. Lógica dialética. Tradução de Carlos Nelson Coutinho. $3^{\text {a }}$ ed. Rio de Janeiro: Civilização Brasileira, 1983.

LEONARD, R. J. Creating a context for game theory. In: WEINTRAUB, E. R. Toward a History of Game Theory, v. 24, p. 29, 1992. Disponível em: < https://books.google.com.br/books?hl=pt$\mathrm{BR} \& \mathrm{lr}=\& \mathrm{id}=9 \mathrm{CHY} 2 \mathrm{Gozh} 1 \mathrm{MC} \& \mathrm{oi}=\mathrm{fnd} \& \mathrm{pg}=\mathrm{PA} 29 \& \mathrm{dq}=$ Creating $+\mathrm{a}+$ context + for + game + theor $\mathrm{y} \&$ ots $=62 \mathrm{dVbhqi6s} \& \operatorname{sig}=\mathrm{Lq} 52 \mathrm{tOHyyx} \operatorname{lgBjGEO} 3 \mathrm{PKj} 6 \mathrm{O} 4 \mathrm{~B} 3 \mathrm{k} \# \mathrm{v}=$ onepage $\& \mathrm{q}=$ Creating $\% 20 \mathrm{a} \%$ 20context\%20for\%20game\%20theory\&f=false>. Acesso em: 05 jan. 2018.

MALINOWSKI, B. A teoria funcional, in Uma teoria científica da cultura. Rio de Janeiro: Zahar, 1970.

MARINHO, R. Prática na teoria: aplicações da teoria dos jogos e da evolução aos negócios. $2^{a}$ ed. São Paulo: Saraiva, 2011.

MIROWSKI, P. What were Von Neumann and Morgenstern trying to accomplish?. In: WEINTRAUB, E. R.. Toward a history of game theory, p. 113-147, 1992. Disponível em: $<$ https://books.google.com.br/books?hl=pt-

BR\&lr=\&id=9CHY2Gozh1MC\&oi=fnd\&pg=PA113\&dq=What+were+Von+Neumann+and+ Morgenstern+trying+to+accomplish\%3F\&ots=62dVbhqj2j\&sig=zSn_74dlw75ZuhTSRilNaOK $\mathrm{hAbI} \# \mathrm{v}=$ onepage $\& \mathrm{q}=$ What $\% 20$ were $\% 20$ Von $\% 20$ Neumann $\% 20$ and $\% 20$ Morgenstern $\% 20$ trying $\% 20$ to\%20accomplish\%3F\&f=false>. Acesso em: $15 \mathrm{dez} .2018$.

MORGENSTERN, O. Preface. In DAVIS, M.D. Game Theory: A nontechnical introduction. New York: Basic Books, 1970.

MUNCK, G. L. Teoria dos jogos e política comparada: novas perspectivas, velhos interesses.

Dados - Revista de Ciências Sociais, vol. 43, n 03. 2000. Disponível em:

http://www.scielo.br/scielo.php?pid=S0011-

52582000000300005\&script=sci_abstract\&tlng=es. Acesso em: 16 dez. 2017. 
NASH, J. Non-cooperative games. Annals of mathematics, Second Series, Vol. 54, No. 2. p. 286-295, 1951. Disponível em: < https://www.jstor.org/stable/1969529>. Acesso em: 10 nov. 2017.

NASH, J. F. Equilibrium points in n-person games. Proceedings of the national academy of sciences, v. 36, n. 1, p. 48-49, 1950. Disponível em:

https://www.ncbi.nlm.nih.gov/pmc/articles/PMC1063129/. Acesso em: 10 nov. 2017.

NASH JR, J. F. The bargaining problem. Econometrica: Journal of the Econometric Society, Vol. 18, No. 2. p. 155-162, 1950. Disponível em:<

http://www.eecs.harvard.edu/ parkes/cs286r/spring02/papers/nash50a.pdf $>$. Acesso em 10 nov. 2017.

NASH, J. Two-person cooperative games. Econometrica: Journal of the Econometric Society, Vol. 21, No. 1.p. 128-140, 1953. Disponível em: < https://www.jstor.org/stable/1906951?seq=1\#page_scan_tab_contents>. Acesso em: 10 nov. 2017.

NEUMANN, J. V.; MORGENSTERN, O. Theory of Games and Economic Behavior. Princeton: Princeton University Press, 1944.

PADOVANI, U; CASTAGNOLA, L. O positivismo, in História da filosofia. São Paulo: Melhoramentos, 1990.

PIMENTA, P. P. G. Kant e a Revolução Copernicana: a razão reflete sobre si mesma. Mente, cérebro \& filosofia: fundamentos para a compreensão da psique. São Paulo: Duetto, 2008.

POPPER, K. A lógica da investigação científica, in Karl Popper, coleção os pensadores. São Paulo: Abril Cultural, 1980.

POUNDSTONE, W. Prisoner's dilemma: John von Neumann, game theory, and the puzzle of the bomb. 1992.

RADCLIFFE-BROWN, A. Sobre o conceito de função em ciências sociais, in Estrutura e função na sociedade primitiva. Petrópolis: Vozes, 1973.

RAWLS, J. A theory of justice. Cambridge: Belknap Press of Harvard, 1971.

RELLSTAB, U. et al. New Insights into the Collaboration between John von Neumann and Oskar Morgenstern on the Theory of Games and Economic Behavior. Durham, NC, Duke University Press, 1992. Disponível em: < https://read.dukeupress.edu/hope/articleabstract/24/Supplement/77/37451/New-Insights-into-the-Collaboration-betweenJohn?redirectedFrom=fulltext $>$. Acesso em: 15 dez. 2017.

SARTINI, B. A., GARBUGIO, G., BORTOLOSSI, H. J., SANTOS, P. A., BARRETO, L. S. Uma introdução à teoria dos jogos. II Bienal da SBM-Universidade Federal da Bahia, 1-61, 2004. Disponível em: https://www.ime.usp.br/ rvicente/IntroTeoriaDosJogos.pdf. Acesso em: 12 dez. 2017.

SÉGUIN, F; CHANLAT, J. F. L'analyse des organisations, une anthologie sociologique. Quebec, Gaëtan Morin, tome 1, p. 65-71, 1987.

SELOTI JR., S. L. Sensemaking em alianças estratégicas: busca, interpretação e ação. Dissertação (Mestrado em Administração de Empresas) - Fundação Getúlio Vargas, São Paulo, 2008 . 
SERVA, M.; DIAS, T.; ALPERSTEDT, G. Paradigma da complexidade e teoria das organizações: uma reflexão epistemológica. Revista de Administração de Empresas, São Paulo, v. 50, n. 3, p. 276-287, jul.-set. 2010. Disponível em:< http://bibliotecadigital.fgv.br/ojs/index.php/rae/article/viewFile/31249/30054>. Acesso em: 15 jan. 2018.

SOUSA, P. H. de. Theory of games and economic behavior: a ideia de ciência de John von Neumann e Oskar Morgenstern. 2005. 102 f. Dissertação (Mestrado em História da Ciência) Pontifícia Universidade Católica de São Paulo, São Paulo, 2005. Disponível em: < https://sapientia.pucsp.br/handle/handle/13416>. Acesso em: 15 out. 2017.

SOUZA, Á.A. A Teoria dos Jogos e as ciências sociais. Marília: Unesp, 2003. Disponível em: $<$ https://alsafi.ead.unesp.br/bitstream/handle/11449/88823/souza_aa_me_mar.pdf?sequence=1 \&isAllowed=y>. Acesso em: 15 dez. 2017.

SPENGLER, F. M.; NETO, T. S. A possibilidade do tratamento de conflitos no âmbito do Judiciário por meio da Teoria dos Jogos. Desenvolvimento em Questão, v. 7, n. 13, p. 63-86, 2009.

XAVIER, O. M. A origem da teoria dos jogos e a existência de equilíbrio em Nash.

Monografia - Faculdade de Ciências Econômicas. Curso de Ciências Econômicas Universidade Federal do Rio Grande do Sul. 2013. Disponível em:<

http://www.lume.ufrgs.br/handle/10183/97708>. Acesso em: 20 jan. 2018. 